\title{
3D models based on Biomechanical analysis and its effect on the performance level of Overhead Serve skill in volleyball
}

\author{
Dr. Ayat Abdel Halim Mohamed
}

Doctor Lecture at Dept. of Training of sports games. Faculty of P.E for girls, University of Helwan, Arab Republic of Egypt.

\begin{abstract}
The main aim of this study was designing interactive 3D models program for overhead serve in basketball and study its effect on player and junior sports' skill performance level. The experimental approach was used for two groups, one experimental and the other controlled, using pre- post measurements for each group. The research society consisted of 160 students in the preparatory stage in 2018/2019. The basic sample was randomly selected from the female students of the research society. The program (3D models) was implemented on the basic study sample (50 students) according to the time distribution. Rustles: There are statistically significant differences in post measurements at a significant level (0.05) between the three-dimensional models group, traditional program group for the skill level of overhead serve in volleyball in favor to the interactive program group using the three-dimensional models.
\end{abstract}

Keywords: Biomechanics, performance level, volleyball

\section{Introduction}

$3 \mathrm{D}$ models is at the forefront of science, which seeks to develop its content and concept from time to time, according to the changes of the modern era, which is characterized by the revolution of information and knowledge and technology in various fields. 3D models considers that improving performance does not only mean the development of knowledge but the ability to apply it. Education technology aims to increase productivity at the individual and enterprise levels. [23]

On the other hand, the technology provides many methods that are characterized by practicality and dynamism; it transcends space and time in providing knowledge and experience. It also offers many educational alternatives from sound recordings, films, slides, and simulations to enrich the educational process, cooping the cognitive explosion in terms of the diversity of sources of knowledge provided to learners. [17]

The technology emphasizes the need to connect students and practitioners, and that the learner, player and junior sports must employ what he has learned in his life beyond the boundaries of the school. It also emphasizes that the goal of education 
today is not only to retain information or to acquire knowledge, but to go further, and to go deeper, where interaction, partnership, cooperation and harmony. The greater the degree of interaction and harmony between the components of the learning system, the greater the chances of learning. Today, the learner is not an acquirer of knowledge but an explorer, a creator and a publisher, ensuring that the learner becomes more productive and more active and positive in educational situations. So it is important to identify learning tasks and how to measure them in the educational design process. [9]

Models are replications of real things that are modified and are an important tool in many lessons, it may be smaller and larger than the original and may be for tools, devices, objects or poses. [8]

A clear definition of models is as Computer simulation of physical phenomena by the preparation of dimensions data for 3D graphics, allow the creation of more realistic models with three dimensions on the axis of height, width and depth $\mathrm{X}, \mathrm{Y}$, $\mathrm{Z}$ for the body and called the applications of modeling or 3D models. [25]

Volleyball is a popular team sport in which two teams of six players are separated by a net. Each team tries to score points by grounding a ball on the other team's court under organized rules. [12]
Coaching for volleyball can be classified under two main categories: match coaching and developmental coaching. The objective of match coaching is to win a match by managing a team's strategy. Developmental coaching emphasizes player development through the reinforcement of basic skills during exercises known as "drills." Drills promote repetition and refinement of volleyball movements, particularly in footwork patterns, body positioning relative to others, and ball contact. A coach will construct drills that simulate match situations thereby encouraging speed of movement, anticipation, timing, communication, and team-work. At the various stages of a player's career, a coach will tailor drills to meet the strategic requirements of the team. The American Volleyball Coaches Association is the largest organization in the world dedicated exclusively to volleyball coaching. [6][7]

\section{Serve:}

A player stands behind the inline and serves the ball, in an attempt to drive it into the opponent's court. The main objective is to make it land inside the court; it is also desirable to set the ball's direction, speed and acceleration so that it becomes difficult for the receiver to handle it properly.[3] A serve is called an "ace" when the ball lands directly onto the court or travels 
outside the court after being touched by an opponent; when only the only player on the server's team to touch the ball is the server.

Through the practical observation and supervision of practical education schools, the researcher noted that Overhead serve skill's performance level for the player and junior sports in is characterized by randomness, poor performance and lack of coordination in motor sequence, and player and junior sports cannot develop a correct perception of the skill in mind which leads to weak performance level.

Through the practical observation and supervision of practical education schools, the researcher noted that Overhead serve skill's performance level for the player and junior sports in is characterized by randomness, poor performance and lack of coordination in motor sequence, and player and junior sports cannot develop a correct perception of the skill in mind which leads to weak performance level.

Therefore, this study is an attempt to teach player and junior sports with one of the most modern techniques in the field of volleyball teaching, by designing a program using 3D interactive models based on biomechanical analysis for study its effect on enhancing player and junior sports skill`s performance level. Thus, studying the impact of an innovative educational technology
(3D based on biomechanical analysis) on volleyball motor skill`s performance.

\section{Objective:}

The main aim of this study was designing interactive 3D models program for overhead serve in basketball and study its effect on player and junior sports' skill performance level.

\section{Research hypothesis:}

There are statistically significant differences between the experimental and controlled groups in post measurements in the skill level of overhead serve in favor to the experimental group.

Method:

The experimental approach was used for two groups, one experimental and the other controlled, using pre- post measurements for each group.

\section{Research sample:}

The research society consisted of 160 students in the preparatory stage in 2018/2019. The basic sample was randomly selected from the female students of the research society. The total number of the sample was 50 students with $31.25 \%$ of the total population. And (20) students by $12.50 \%$ of the total research community and outside the basic research sample as exploration sample to obtain scientific validity, and test the designed interactive 
three-dimensional models, and the sample was divided as follows:

- Experimental group: uses the designed interactive 3D models, (25) students.

- Controlled group: uses the traditional method of "traditional program" (25) students.

\section{Tools:}

1. Data recording forms: (Appendix 1): Forms for recording the measurements and data for the sample: name, age, height, weight, intelligence score, fitness test scores, and the skill test score skill for overhead serve were designed.

2. Tools and devices: Restameter device for measuring height and weight, distance tape measure, Bearings, medical balls, tennis balls, volleyballs, volleyball court

3. IQ test (Appendix 2): The IQ test for the preparatory stage, prepared by Ahmed Saleh (2008). [4]

\section{Results:}

Table (1) Validity and stability of IQ test $\mathrm{N}=20$ (test validity), $\mathrm{N}=14$ (test stability)

\begin{tabular}{|c|c|c|c|c|c|c|c|}
\hline \multirow[t]{2}{*}{ Variables } & \multirow[t]{2}{*}{ unit } & \multicolumn{2}{|c|}{$\begin{array}{c}\text { upper } \\
7=N_{1}(33 \%)\end{array}$} & \multicolumn{2}{|c|}{$\begin{array}{c}\text { lower } \\
7=\mathrm{N}_{2}(33 \%)\end{array}$} & \multirow{2}{*}{$\begin{array}{c}\text { Mean } \\
\text { differences }\end{array}$} & \multirow[t]{2}{*}{ T. value } \\
\hline & & $\mathrm{M}$ & $\pm \mathrm{SD}$ & $\mathrm{M}$ & $\pm \mathrm{SD}$ & & \\
\hline IQ test & Degree & 46.22 & 1.35 & 36.9 & 0.88 & 9.32 & $14.98 *$ \\
\hline \multirow{2}{*}{ Variables } & \multirow{2}{*}{ unit } & \multicolumn{2}{|c|}{$\mathbf{1}_{\text {st }}$} & \multicolumn{2}{|c|}{2 n.d } & \multirow{2}{*}{\multicolumn{2}{|c|}{$\mathrm{CC}$}} \\
\hline & & M & $\pm \mathrm{SD}$ & M & $\pm \mathrm{SD}$ & & \\
\hline IQ test & Degree & 40.12 & 4.84 & 40.96 & 5.52 & & \\
\hline
\end{tabular}

Shows the significant level $\mathrm{p}<0.05$

It is clear from Table (1) that there are statistically significant differences between the two upper, lower groups in favor of the upper group, indicating the validity of the tests. It is also evident that there is a correlation between the first and second applications indicating the stability of the tests.

4. Fitness elements tests: (Appendix 3, 4) The fitness elements tests for the overhead serve skill were identified through the following scientific studies and references: [2][20][10][16][20][26][28]
5. Overhead serve skill test (Appendix5):Through the following scientific studies and references (which has been reviewed or identified): [1][5][16][20], The skillful test was determined to measure the level of performance of the overhead serve. In addition, the expert opinion (Appendix8) was used to determine the tests to measure the skill, Experts agreed to the test of (Overhead serve accuracy for specific places) as shown in 
Appendix (5).

6. Kinovea-0.8.15

video biomechanical analysis software: Video analysis software was used to analyze the performance and measure body segment's angles for the analysis sample.

7. DAZ Studio 4.9 (64-bit) software: to design the $3 \mathrm{D}$ educational models in accordance with the extracted data from the biomechanical analysis.

Technology programes (threedimensional models based on biomechanical analysis):

A. Program design of threedimensional models

The interactive program was designed using 3D models as shown below:

- The goal is to design an interactive program using 3D models based on biomechanical analysis to know its effect on the performance level of the overhead serve skill in volleyball.

-The education content was analyzed through the curriculum (Ministry of Education 2011), In addition the following references that describing the skill (Farid et al., 2012 ) , ( Zaki 2012 ), (Mohamed, Hamdy 2005),(Tarek, Ayman 2006), (Ahmed 2007), (Ayat 2017), (Rehab, Abdallah and Khaled 2013), which was used when designing the 3D interactive program.

- The technical performance of the skill in question was analyzed according to the stages of technical performance shown in appendix 6 according to the following stages:
A. Preparatory stage.
B. The main stage.
C. The final stage. (appendix 6), [1][5][16][20][21]

- Using the Kinovea-0.8.15 video analysis software to analyze the angles of the body parts during performance considering the following model of body parts consisting of (11) part representing the trunk, arms, and legs, as shown in Figure (1).

Figure (1) Body parts model used in skill motor analysis

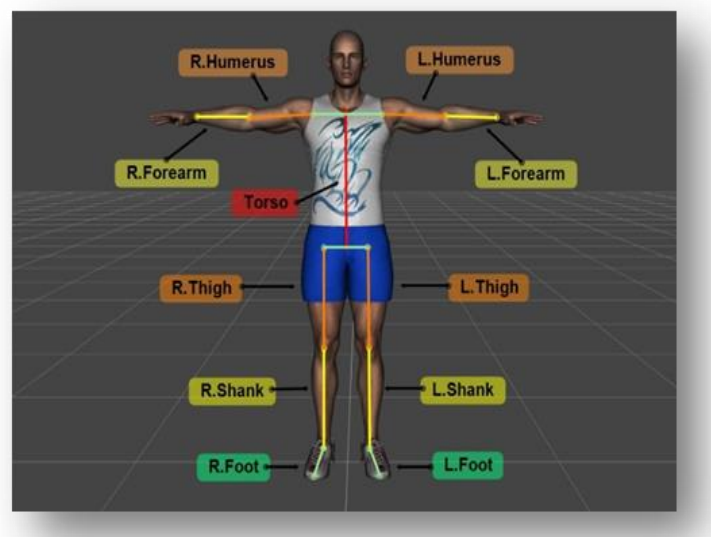

- 10 different frames representing were analyzed at different and successive stages of the above mentioned technical performance in appendix (6).

- The body parts angles were mainly based on the analysis for later use in the design of the skill 3D interactive models according to the 
steps and procedures of 3D model design suggested by (Talha A. 2016). [22]

- The measurement of the body parts angles (as shown in Table 4) was from the positive horizontal axis $(+$ $x)$, while the center of the coordinate system (y, $\mathrm{x})$ was positioned on the spindle of the part to be measured (z) as showed in figure (2). The measurements of the angles can be ascertained when used in the interactive modeling process. This method of measurement follows the principles of direct linear transformation theory, which gives constant measurements of angles regardless of distance, scale, or size (Rasmussen et al., 2005). [19]

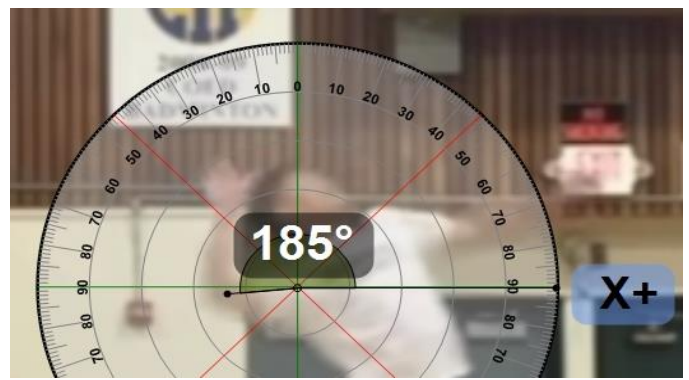

Figure (2) measurement model of one of the angles (humerus angle) form the positive horizontal axis

- After the biomechanical analysis of the skill in question, the data derived from the analysis of the angles measurement was used according to the method used in Figure (2) for the design of the skill interactive models by DAZ Studio 4.9 (64-bit) software for 3D modeling According to the angles of the body parts and stages of the technical performance of the skill.

- the researcher was able to design (10) static models representing different moments during the performance.

- Based on the (10) static models, the researcher designed additional (271) models to generate a complete dynamic 3D motion model of the overhead serve with the benefit of immersive interaction between learners and models.

- The skill technical points were demonstrated on the threedimensional model using the Active presenter software as shown in appendix (7) and the following Figures:

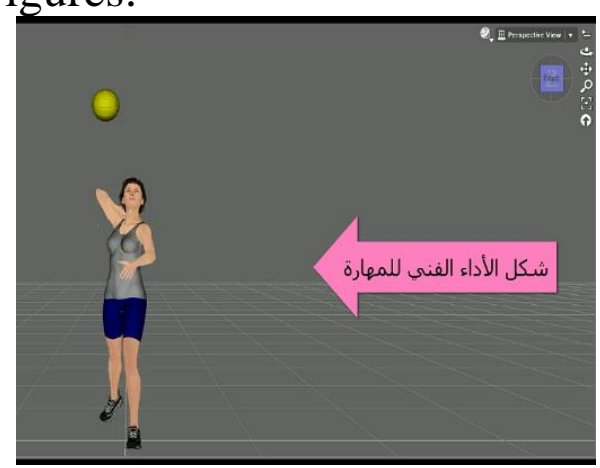

- The experts' opinion of the 3D interactive program (appendix 7) was reviewed and agreement was obtained on the validity of the interactive software for the skill 3D models and program.

- The proposed 3D interactive models were tested on a sample of the exploratory study to determine the suitability of the interactive program for the sample. This experiment resulted in the clarity of 
all the contents of the 3D modeling software among the sample students of the exploratory study.

Application of the program:

The program (3D models) was implemented on the basic study sample (50 students) according to the time distribution, as shown in the following table:

Table (7) Time distribution of the program content for the two research groups

\begin{tabular}{|c|c|c|c|}
\hline $\begin{array}{c}\text { Content } \\
\text { (3D models) }\end{array}$ & \multicolumn{3}{|c|}{ Time } \\
\hline Program Duration & \multicolumn{3}{|c|}{2 months } \\
\hline Unit Number & \multicolumn{3}{|c|}{8 Units } \\
\hline \multirow{3}{*}{ Unit time } & \multicolumn{3}{|c|}{$45 \mathrm{~m}$} \\
\hline & Introductory & Main & Final \\
\hline & $10 \mathrm{~m}$ & $30 \mathrm{~m}$ & $5 \mathrm{~m}$ \\
\hline Total program time & \multicolumn{3}{|c|}{$360 \mathrm{M}$} \\
\hline
\end{tabular}

- The time distribution of the program was standardized for the two groups, and the difference was only in the learning method for each group. The experimental group was learn by the interactive program using the 3D models. The controlled group was through traditional program.
- Before the interaction of each student alone with the threedimensional program. The skill performance was presented continuously in order to form a general perception of the skill for player and junior sports.

\section{Result :}

Table (8) Significance of the mean differences between the pre- post and post-post measurements of the two Experimental groups in the level of Overhead serve performance in volleyball

\begin{tabular}{|c|c|c|c|c|c|c|}
\hline \multirow{4}{*}{ Parameters } & \multicolumn{4}{|c|}{ Post measurement } & \multirow{4}{*}{$\begin{array}{c}\text { Mean } \\
\text { Differences }\end{array}$} & \multirow{4}{*}{$\mathrm{T}$ value } \\
\hline & \multirow{2}{*}{\multicolumn{2}{|c|}{ Experimental }} & \multirow{2}{*}{\multicolumn{2}{|c|}{ Controlled }} & & \\
\hline & & & & & & \\
\hline & $\mathrm{M}$ & $\pm \mathrm{SD}$ & $\mathrm{M}$ & $\pm \mathrm{SD}$ & & \\
\hline Overhead serve performance & 15.26 & 2.58 & 12.03 & 2.55 & 3.23 & $8.66^{*}$ \\
\hline
\end{tabular}

Shows the significant level $\mathrm{p}<0.05$

Table (8) shows statistically

Discussion significant differences between PrePost measurements of both two experimental groups, as well as in post measurements between the two groups at a significant level of 0.05 .
The results of Table (8) show that there are statistically significant differences in post mean values between the two groups where the value of calculated (t) (3.88) is greater than the value of table $(\mathrm{t})$ at 
a significant level (0.05), which indicates the higher level of skill performance for the experimental group (interactive models group) than the controlled group.

This indicates that the progress in the skill level of the experimental group compared to the controlled group is due to the reliance on the 3D interactive program and the diversity of models, images, sound, and video, thus the positive impact on the level of performance of the skill due to the attractiveness and effectiveness of the three-dimensional models.

The researcher also explains the reason for these differences to the effect of the interactive program using three-dimensional models, which helped to raise the interest of player and junior sports and motivate them to exert effort during the skill performance. Also, these differences between the two groups indicate a better understanding of the skill in question and better assimilation.

This indicates that the 3D interactive program helped player and junior sports seing good performance through 3D models from different angles and gave player and junior sports the facility to see all the details of performance either from the front, back, one side or from the top and bottom and from any angle wanted player and junior sports and thus the player and junior sports able to see the different body angles. Thus, The interactive program using the threedimensional models have a positive effect on the skillful learning under research in volleyball compared to the traditional program.

The researcher attributed the reason for the preference of the three-dimensional models group compared to the traditional program group that the player and junior sports of the experimental group (three-dimensional models) had the opportunity to imagine the correct performance free of errors because of the use of interactive models when watching the skill on the Active presenter program where they were briefed on the details of performance and the best technical aspects of the skill which was reflected positively on the level of skill performance of the experimental group compared to the controlled group, and the above is consistent with the following studies: [15][18]

Therefore, the hypothesis is achieved, which stated that there are statistically significant differences between the two groups in post measurements for the skill level of overhead serve in favor to the experimental group (threedimensional models based on biomechanical analysis).

\section{Conclusion}

There are statistically significant differences in post measurements at a significant level 
(0.05) between the threedimensional models group, traditional program group for the skill level of overhead serve in volleyball in favor to the interactive program group using the threedimensional models.

\section{Recommendations}

- Encouraging the use of 3D models program for middle school player and junior sports because of its effect in raising the level of skillful performance.

- Introducing programs designed through interactive models in the curricula of the middle schools (the preparatory schools).

- The need to benefit from the expertise of specialists in the field of education technology by holding seminars and lectures in the educational institutions to raise awareness of the importance of interactive models in the educational process.

\section{References}

1 - Afaf Mohamed Khattaby, Elham Abdel Moneim Ahmed, Dalia Mohamed Hashim: Applications in Volleyball, Helwan university press, Faculty of physical education, Helwan university 2014.

2 - Ahmed Rady Elawaty: "A training program for the development of traffic forecasting components and its impact on the performance level of some defense skills for volleyball players" Unpublished Master thesis, Faculty of Physical Education in Fleming, Alexandria University 2013.

3 - Ahmed Talaat Abu Zeid: "The impact of educational program using multimedia on cognitive achievement and the level of basic skills in volleyball for middle school students" Unpublished Master thesis, Faculty of Physical Education, Mansoura University 2007.

4 - Ahmed Zaki Saleh: Educational Psychology, Edition 14, Library of AlNahda Egyptian, Cairo 2008.

5 - Ayat Abdel-Halim Mohamed Aly: Learning by technological modeling and its effect on the performance level of Overhead Serve skill in volleyball, Scientific Journal of Sports Sciences \& Arts. (Publications; search number 110, part 2, June 2020, ISSN 1110-8460-2020102) at www.ijssa-gezira.com. Faculty of P.E for girls, University of Helwan, 27 June 2017.

6 - Bean, Josh. "Volleyball gets new look with 'libero'". Times Daily. (Florence, Alabama). p. 6C, September 30, 2015.

7 - Bosak, Chris. Volleyball, https://en.wikipedia.org/wiki/Volleyball\# cite_ref-:1_3-8, January 5, 2019.

8 - Essam El-Din Metwally Abdallah: Methods of teaching physical education between theory and practice - the world of sports publishing and Dar Al-Wafa for printing - Alexandria 2018.

9 - Facer, K. \& Sandford, R.: The next 25 years?: Future scenarios and future directions for education and technology. Journal of Computer Assisted Learning , 26, 74 - 93 . doi: 10.1111/j.1365-

2729.2009.00337.x [Crossref], [Web of Science $\circledR$ ], [Google Scholar], 2010.

10 - Farid Abdel Fattah Khashaba, Hossam Khalifa, Mahmoud Metwally: Fundamentals of volleyball between theory and application, Rashid Press, second edition, Cairo, Arab Republic of Egypt. pp 45, 2012.

11 - Joel., Dearing. Volleyball fundamentals. Champaign, IL: Human Kinetics, 2003.

12

Hillary."Volleyball". International 
Olympic Committee. Retrieved2007-0321.at

https://en.wikipedia.org/wiki/Volleyball\# cite ref-1, January 2019.

13 - Ministry of Education: Teacher's Guide in Physical Education - Modern Printing House - Cairo 2011.

\section{4 - Mohamed Attia Khamis:}

Theoretical and Historical Assets of ELearning Technology, Edition 2, Dar AlSahab for Printing, Publishing and Distribution, Cairo, Egypt, 2016.

15 - Mohamed Ismail Ibrahim: "The effectiveness of learning using the method of modeling supported by cartoon graphics on the development of some elements of fitness physical education lesson for students of the first cycle of basic education in the city of Minya" Journal of Sports Science - Vol I - December 2013.

16 - Mohamed, S.H., \& Hamdy, A.: The scientific bases of volleyball and measurement methods for evaluating (physically. Skill. Cognitive. Psychological. Analytical), book centre for publishing, second edition, Cairo. Arab Republic of Egypt. pp 34, 2005.

17 - Mustafa Al - Sayeh Mohamed: The Technological Approach, Learning and Information technology in Physical Education - Dar Al - Wafa - Alexandria 2004.

18 - Osman Abdallah: "The impact of a program using super images supported by the model of learning dimensions on some elements of fitness and trends for first cycle of basic education students " Journal of Sports Science - Vol II - Minia December 2013.

19 - Rasmussen J, de Zee M, Damsgaard M, Christensen ST, Marek C, Siebertz K.: A general method for scaling musculoskeletal models. 2005 International Symposium on Computer Simulation in Biomechanics; Cleveland, OH, US, 2005. 20 - Rehab Adel Gabal, Abdallah A. Mohamed and Khaled A. El-Battawy:
"Effects of Teaching Strategy (cooperative learning and computer) on Learning the volleyball skills in P.E. Lesson". Journal of Physical Culture and Sport, Studies and Research, 24th of October 2013, Warsaw, Poland.

\section{1 - Suzanne Badran Sulaiman:} Volleyball, Menoufia university press, Faculty of physical education Sadat university 2007.

22 - Talha A. Hossam El Din: The Biomechanical Parameters For Designing Motor Skill`s 3D Educational Models, The international scientific Journal of physical education and sport sciences. Special issue, 2016.

23 - Tamer El Mallah: Education Technology: The New Concept and its Elements, Faculty of Education, Egypt, at https://www.new-educ.com/,

10

November 2017.

24 - Tarek Mohamed Abdelaziz, Ayman Abdo Mohamed: "The impact of educational program using computer on the level of skill and cognitive achievement in volleyball for students of Physical Education Faculty - Assiut University", Assiut Journal of Sport Sciences and Arts - Volume 4, Assiut University, 2006.

25 - Wescott, Bob: The Every Computer Performance Book, Chapter 7: Modeling Computer

Performance. CreateSpace.ISBN 1482657 759. 2013.

26 - Zaki, M.H.: Teaching volleyball methods. Technical radiation library for publishing, Cairo. Arab Republic of Egypt. pp 40, 2012.

27

http://www.aun.edu.eg/faculty_physical education/arabic/researches.php?Dept_Co $\underline{\mathrm{de}=1001}$

28

http://www.volleyballegypt.com/vb/show thread.php?p=1335 